\title{
Tweets by People With Arthritis During the COVID-19 Pandemic: Content and Sentiment Analysis
}

Danielle Berkovic ${ }^{1}$, BHSc (Hons); Ilana N Ackerman ${ }^{1}$, BPhysio (Hons), PhD; Andrew M Briggs ${ }^{2}$, BSc (Hons), PhD, FACP; Darshini Ayton ${ }^{1}$, BBiomedSci (Hons), MPH, PhD

${ }^{1}$ School of Public Health and Preventive Medicine, Monash University, Melbourne, Australia

${ }^{2}$ School of Physiotherapy and Exercise Science, Curtin University, Perth, Australia

Corresponding Author:

Darshini Ayton, BBiomedSci (Hons), MPH, PhD

School of Public Health and Preventive Medicine

Monash University

Melbourne,

Australia

Phone: 61425705130

Email: darshini.ayton@monash.edu

\section{Abstract}

Background: Emerging evidence suggests that people with arthritis are reporting increased physical pain and psychological distress during the COVID-19 pandemic. At the same time, Twitter's daily usage has surged by $23 \%$ throughout the pandemic period, presenting a unique opportunity to assess the content and sentiment of tweets. Individuals with arthritis use Twitter to communicate with peers, and to receive up-to-date information from health professionals and services about novel therapies and management techniques.

Objective: The aim of this research was to identify proxy topics of importance for individuals with arthritis during the COVID-19 pandemic, and to explore the emotional context of tweets by people with arthritis during the early phase of the pandemic.

Methods: From March 20 to April 20, 2020, publicly available tweets posted in English and with hashtag combinations related to arthritis and COVID-19 were extracted retrospectively from Twitter. Content analysis was used to identify common themes within tweets, and sentiment analysis was used to examine positive and negative emotions in themes to understand the COVID-19 experiences of people with arthritis.

Results: In total, 149 tweets were analyzed. The majority of tweeters were female and were from the United States. Tweeters reported a range of arthritis conditions, including rheumatoid arthritis, systemic lupus erythematosus, and psoriatic arthritis. Seven themes were identified: health care experiences, personal stories, links to relevant blogs, discussion of arthritis-related symptoms, advice sharing, messages of positivity, and stay-at-home messaging. Sentiment analysis demonstrated marked anxiety around medication shortages, increased physical symptom burden, and strong desire for trustworthy information and emotional connection.

Conclusions: Tweets by people with arthritis highlight the multitude of concurrent concerns during the COVID-19 pandemic. Understanding these concerns, which include heightened physical and psychological symptoms in the context of treatment misinformation, may assist clinicians to provide person-centered care during this time of great health uncertainty.

(J Med Internet Res 2020;22(12):e24550) doi: $10.2196 / 24550$

\section{KEYWORDS}

COVID-19; SARS-CoV-2; novel coronavirus; social media; Twitter; content analysis; sentiment analysis; microblogging; arthritis

\section{Introduction}

Social media contains a plethora of health information pertaining to individuals living with chronic illness [1,2]. Social media provides a unique opportunity to observe thoughts, feelings, and interactions between individuals living with chronic illness, and to leverage this information to promote positive health outcomes [3,4]. The COVID-19 pandemic has seen widespread uptake of social media use. Twitter, a well-known social media platform primarily used for microblogging, plays a significant role in crisis communications and can be a powerful tool to communicate to entire populations during a time of rapid change [5]. Twitter is already frequently used by individuals with arthritis to communicate with peers [6] and to receive up-to-date 
information from health professionals and services about novel therapies and management techniques [7].

Many inflammatory arthritis medications act as immunosuppressants, which are advantageous in controlling arthritis-mediated inflammatory responses, but can increase the risk of infection [8]. Long-term use of immune-modulating therapies or glucocorticoids may place individuals with arthritis in a higher-risk category for contracting the novel coronavirus SARS-CoV-2, although the level of risk is poorly understood [9-12]. Current guidelines suggest that individuals living with arthritis should physically distance from other individuals and their communities [13], and will likely need to do so for a longer duration than the general public. Heightened stress due to potential medication shortages, reduced opportunities to personally consult health care professionals, and enforced limitations on physical activity (which, for many, is a core component of arthritis self-management [14]) contribute to worsening arthritis symptoms, including disease flares. At present, individuals with arthritis have already reported increased physical pain and psychological distress during the COVID-19 pandemic [15,16].

In the current COVID-19 outbreak, Twitter's overall daily usage has surged by $23 \%$ in 2020 [17], presenting a unique opportunity to assess the content and sentiment of tweets. Examining publicly available tweets allows exploration of important proxy topics through microblogging data, without directly burdening this population. This research aims to identify proxy topics of importance for people with arthritis (of any diagnostic category) during the COVID-19 pandemic by characterizing the textual content and sentiment of tweets, and to explore the emotional context of tweets by people with arthritis during the early phase of the pandemic.

\section{Methods}

\section{Design}

An exploratory content and sentiment analysis was undertaken. All data were collected and reported according to the terms and conditions of Twitter, which state that content posted by individuals is publicly available to syndicate, broadcast, distribute, retweet, promote, or publish, excluding private information (eg, home addresses or identity documents) [18]. Use of tweets by individuals outside of Twitter can be carried out with no compensation paid to the individual tweeter, as use of Twitter is agreed upon as sufficient compensation [18]. The Monash University Human Research Ethics Committee (Project ID 24354) approved this project.

\section{Inclusion and Exclusion Criteria}

Publicly available tweets posted in English or with English translation (automated through Twitter), with the hashtags shown in Table 1 were included.

Table 1. Hashtags categorized by topic.

\begin{tabular}{ll}
\hline Topic & Hashtag \\
\hline COVID-19 & $\bullet$ \#coronavirus \\
& $\bullet$ \#covid19 \\
& $\bullet \quad$ \#isolation \\
& $\bullet \quad$ \#socialdistancing \\
Arthritis & $\bullet \quad$ \#arthritis \\
& $\bullet \quad$ \#spoonie \\
& $\bullet$ \#rheumatologist
\end{tabular}

Hashtags were selected based on trialing various combinations through Twitter's search function. The highest number of tweets retrieved were for the hashtags \#coronavirus, \#covid19, \#arthritis, and \#spoonie (the latter term coined by people living with chronic illness to describe various methods of pain management [7]). Hashtags were also searched as words; for example, where \#arthritis was searched, arthritis without a hashtag was searched as well. This ensured that specific arthritis types mentioned in tweets without hashtags (eg, rheumatoid arthritis or psoriatic arthritis) were included. Hashtags and words were combined through the advanced search function on Twitter using the domains Hashtags, Words, Language, and Dates (Figure 1 [19]). Tweets were excluded if they originated from organizations, news outlets, or health professionals rather than individuals in order to focus on the personal perspective. 
Figure 1. The advanced search function on Twitter [19].

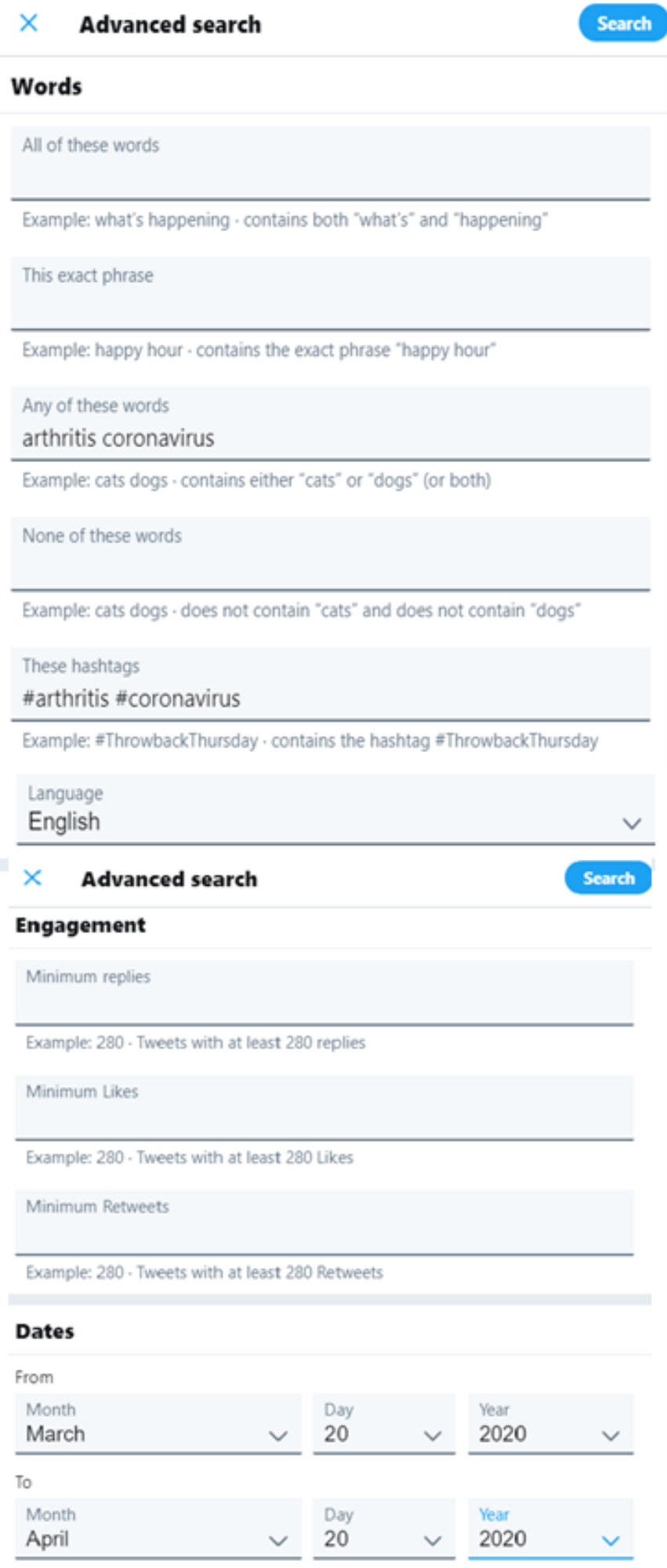

\section{Data Collection}

Tweets were retrospectively extracted from March 20 to April 20, 2020. The search strategy and search results are included in Multimedia Appendix 1. The search timeframe was chosen to align with the early phase of the COVID-19 pandemic and the period when many developed countries (eg, the United States, the United Kingdom, Italy, Australia) announced enforceable physical distancing or isolation measures [20-23].
The desktop version of the Twitter website (versus the mobile app) was used for data collection for ethical purposes with only publicly available tweets extracted, rather than through a private login. In addition to the tweets themselves, accompanying data fields were extracted from each tweet using a customized template. Extracted data fields included (where possible): Twitter profile blurb, gender of tweeter, country of tweeter, number of likes, number of retweets, number of replies, hashtags used, number of hashtags, and use of accompanying photos. 
Data were stored in a Microsoft Excel spreadsheet (v16.0, Microsoft Corp).

\section{Data Analysis}

To address the research aims, two data analysis techniques were utilized: summative content analysis and sentiment analysis. Content analysis was used to characterize the textual contents of tweets related to arthritis and COVID-19. Content analysis is exploratory; it aims to quantify and describe unknown phenomena [24]. During the content analysis process, the primary researcher (DB) read each tweet and categorized the tweets into a representative theme and subtheme related to a topic of importance for people with arthritis during the study period.

Summative content analysis occurred through a process of coding, which involved counting and comparisons of Twitter content, followed by interpretation of the underlying context [25]. To begin with, the first 10 tweets were analyzed and allocated a summary code. The code represents the theme of a tweet (eg, "health care experiences"). As additional tweets were examined, they were given one of the original codes or allocated a new code based on new content. This process was repeated until each tweet was coded and themed. Once these original themes were finalized, they were recoded for additional context, and a second researcher (DA) checked the coding. For example, "health care experiences" was coded for similarities in people's health care experiences, such as difficulties accessing medications. Given Twitter's character limits, each tweet only contained one theme. The frequency of original themes and subthemes was counted to indicate importance [26].

Sentiment analysis enables an examination of written and spoken words for positive and/or negative emotion. When applied to health care or social media research, sentiment analysis facilitates interpretation of textual information about patient experience from a person-centered perspective [27]. Once tweets were coded and categorized into themes, sentiment analysis was employed to assess the emotion associated with the theme using
Glaser and Strauss's [28] 6 codes for sentiment analysis, a common framework used for Twitter-based research [29,30]:

1. No sentiment: the tweet has no emotion or words or special punctuation; is matter-of-fact sounding;

2. Wretched: the tweet is purely negative;

3. Bad: the tweet contains mainly negative phrases and words that outweigh any positive sentiment;

4. So-so: the tweet has a mediocre and balanced sentiment where positive and negative statements are balanced;

5. Swell: the tweet contains mainly positive phrases and words which outweigh negative sentiment;

6. Great: the tweet is purely positive.

The presence of emojis, which are shorthand facial expression symbols that are frequently used to facilitate communication of mood and emotion, in tweets were also analyzed. To provide information regarding the emotional content of the tweets, Emoji Sentiment Ranking, as outlined by Kralj Novak et al [31], was applied. Tweets containing an emoji were categorized into one of three sentiment scores: (1) negative, (2) neutral, and (3) positive. Together, the content and sentiment analyses provide a proxy indicator of the topics of interest for, and perceived emotions of, people with arthritis during the COVID-19 pandemic.

Even in social media studies, it is imperative to protect participant anonymity [32]. To avoid reverse identification of participants based on their tweets (which can be found through internet searches), tweets analyzed in this study are not quoted verbatim. Instead, all data are expressed in aggregate form through descriptive statistics and qualitative syntheses.

\section{Results}

The analysis included 149 tweets posted during the study period. The majority of tweeters were female and based in the United States. The most common arthritis type was rheumatoid arthritis. Table 2 outlines gender, country of residence, and arthritis type. 
Table 2. Demographics of Twitter users sampled.

\begin{tabular}{|c|c|}
\hline Characteristic & Users $(\mathrm{N}=149), \mathrm{n}(\%)$ \\
\hline \multicolumn{2}{|l|}{ Gender } \\
\hline Female & $105(70.0)$ \\
\hline Male & $31(21.0)$ \\
\hline Unknown & $13(9.0)$ \\
\hline \multicolumn{2}{|l|}{ Country } \\
\hline United States & $68(45.5)$ \\
\hline United Kingdom and Northern Ireland & $39(26)$ \\
\hline Canada & $18(12.0)$ \\
\hline Australia & $1(0.7)$ \\
\hline France & $1(0.7)$ \\
\hline Germany & $1(0.7)$ \\
\hline India & $1(0.7)$ \\
\hline New Zealand & $1(0.7)$ \\
\hline Unknown & $19(13.0)$ \\
\hline \multicolumn{2}{|l|}{ Diagnostic category } \\
\hline Arthritis (specific arthritis type unclear) & $86(58.0)$ \\
\hline Rheumatoid arthritis & $32(21.0)$ \\
\hline Systemic lupus erythematosus & $12(8.0)$ \\
\hline Psoriatic arthritis & $10(7.0)$ \\
\hline Ankylosing spondylitis & $3(2.0)$ \\
\hline Osteoarthritis & $3(2.0)$ \\
\hline Juvenile idiopathic arthritis & $3(2.0)$ \\
\hline
\end{tabular}

Content analysis revealed seven themes from the tweets: (1) arthritis-related symptoms, (5) advice sharing, (6) messages of health care experiences, (2) personal stories, (3) links to or positivity, and (7) stay-at-home messaging. Table 3 details the advertisements of relevant blogs, (4) discussion of original themes and subthemes. 
Table 3. Content analysis of themes and subthemes.

\begin{tabular}{|c|c|c|}
\hline Theme and subthemes & Tweets, n (\%) & Examples of phrases or \#hashtags describing content \\
\hline Health care experiences & $55(37.0)$ & - "I'm a long-term user of \#hydroxychloroquine" \\
\hline Difficulties accessing hydroxychloroquine & $20(36.5)$ & - "\#Hydroxychloroquine destroyed my red blood cells" \\
\hline Past experiences using hydroxychloroquine & $20(36.5)$ & \\
\hline $\begin{array}{l}\text { Support for President Trump's advice to use hydroxychloro- } \\
\text { quine to cure COVID-19 }\end{array}$ & $9(16.0)$ & \\
\hline Experiences within the National Health Service (UK NHS) & $4(7.0)$ & \\
\hline Managing medication changes during COVID-19 & $2(4.0)$ & \\
\hline Personal stories & $29(20.0)$ & - "My rheumatologist has asked that I go into isolation. Now \\
\hline $\begin{array}{l}\text { Explanation of history of managing arthritis, and subsequent } \\
\text { fears of contracting or dying from COVID- } 19\end{array}$ & $9(31.0)$ & $\begin{array}{l}\text { all I can do is enjoy the world from my window" } \\
\text { "My immune system is compromised but I'm being told } \\
\text { to go to a germy hospital???" }\end{array}$ \\
\hline $\begin{array}{l}\text { Description of ways to self-manage physical symptoms (eg, } \\
\text { exercising, staying connected with friends) }\end{array}$ & $7(24.0)$ & \\
\hline Physical and psychological challenges of socially distancing & $7(24.0)$ & \\
\hline $\begin{array}{l}\text { Perceived barriers to attending rheumatologist appointments } \\
\text { (eg, discomfort of wearing masks, fear of entering a high-risk } \\
\text { location) }\end{array}$ & $6(21.0)$ & \\
\hline Links to or advertisements of relevant blogs and forums & $22(14.0)$ & - "To our members, subscribers, followers, and fans: we are \\
\hline $\begin{array}{l}\text { Recommendations and links from individuals to official pa- } \\
\text { tient- and consumer-led blogs (eg, CreakyJoints) }\end{array}$ & $10(45.0)$ & \\
\hline $\begin{array}{l}\text { Personal blogs on individual COVID-19 experiences (eg, how } \\
\text { to manage worsening symptoms) }\end{array}$ & $7(32.0)$ & \\
\hline $\begin{array}{l}\text { Unofficial patient blogs (eg, online communities and forums) } \\
\text { to create support networks for individuals }\end{array}$ & $5(23.0)$ & \\
\hline Discussion of arthritis-related symptoms & $15(10.0)$ & - “Anyone else's arthritis flaring due to extra phone use?" \\
\hline Increased physical pain & $11(73.5)$ & \\
\hline Difficulty sleeping & $2(13.5)$ & \\
\hline Reduced dexterity & $2(13.5)$ & \\
\hline Advice seeking and sharing & $14(9.0)$ & - "Any suggestions for chronic pain sufferers? Coronavirus \\
\hline $\begin{array}{l}\text { Questions directed at government bodies (eg, the NHS and } \\
\text { national working-from-home regulations) }\end{array}$ & $5(36.0)$ & - $\quad$ "Do we know if those of us with autoimmune conditions \\
\hline $\begin{array}{l}\text { Seeking advice from physiotherapists on at-home exercises } \\
\text { to manage physical symptom burden }\end{array}$ & $3(22.0)$ & (arthritis) have a higher risk from \#coronavirus" \\
\hline $\begin{array}{l}\text { Advice on whether to temporarily cease taking immunosup- } \\
\text { pressant medications }\end{array}$ & $2(14.0)$ & \\
\hline $\begin{array}{l}\text { Advice on how to protect airways if dexterity limitations pre- } \\
\text { vent mask-wearing }\end{array}$ & $2(14.0)$ & \\
\hline Questions directed to delivery services regarding delays & $2(14.0)$ & \\
\hline Messages of positivity & $8(6.0)$ & - "It's amazing how motivating isolation can be! On my \\
\hline $\begin{array}{l}\text { Gratitude for friends, family, and to still be able to appreciate } \\
\text { life }\end{array}$ & $4(50.0)$ & \\
\hline $\begin{array}{l}\text { Spare time as a result of physical distancing facilitating more } \\
\text { time to exercise and reduce physical symptom burden }\end{array}$ & $4(50.0)$ & \\
\hline Stay-at-home messaging & $6(4.0)$ & - \#stayathome \\
\hline Emotional appeals for people to stay at home & $4(67.0)$ & - $\quad$ \#arthritissucks \\
\hline Angry appeals for people to stay at home & $2(33.0)$ & - \#arthritiswarrior \\
\hline
\end{tabular}

The most common theme identified was experiences of pandemic. Hydroxychloroquine (brand name Plaquenil) featured navigating the health care system during the COVID-19 prominently in tweets, in terms of difficulties accessing the 
medication, past experiences using the medication, and recommendations from the President of the United States to use this medication to cure or prevent COVID-19, despite the lack of evidence or medical advice. Some individuals tweeted about their experiences within the National Health Service (NHS) in the United Kingdom, where patients were subject to longer-than-usual delays for rheumatology appointments, medication infusions, and general health check-ups.

Many individuals used Twitter as a platform to connect with and seek support from peers with arthritis. Tweets contained personal stories, links to personal and consumer-led blogs, discussion of arthritis-related symptoms, and advice seeking and sharing. Some individuals shared their challenges managing arthritis symptoms whilst being confined to their homes and questioned their physical and psychological capacity to function if they were to contract COVID-19. Others described the physical and emotional challenges associated with isolation, including increased physical pain, reduced dexterity, and missing family. Strategies to manage these symptoms included exercising and staying socially connected online with friends to ease mental strain. Tweeters were willing to guide others to potentially helpful resources, particularly blogs run by professional organizations (eg, CreakyJoints, the Arthritis Society [Canada]). Several tweets contained questions were directed toward government bodies (eg, regarding national working-from-home policies), whereas others reached out to physiotherapists or peers with arthritis for advice on appropriate exercises or lifestyle modifications to manage symptom burden during the isolation period. Some tweeters noted dexterity limitations that were highly relevant to COVID-19, such as being incapable of placing a mask behind their ears.

Some tweets were positive with tweeters noting they used their newfound spare time to concentrate on exercise, which was beneficial for mental health and pain reduction. Finally, some individuals expressed their desire for people to stay at home to flatten the curve of infections to return to normal life. Disapproval was voiced toward those refusing to practice physical distancing, whereas others expressed anger toward people not adhering to stay-at-home orders.

Sentiment analysis provided complementary information about the emotions associated with the content analysis themes. Table 4 details the original themes and corresponding sentiment, with phrases or hashtags describing tweeters' personal experiences. 
Table 4. Sentiment analysis of tweets.

\begin{tabular}{|c|c|c|}
\hline Original theme and sentiment ${ }^{\mathrm{a}}$ & Tweets, n (\%) & Examples of phrases or \#hashtags \\
\hline Health care experiences & $55(37.0)$ & \\
\hline Great & $5(9.0)$ & "doddle," "virus gone in 3 days," "NO SIDE EFFECTS," "credible and good" \\
\hline Swell & $3(5.0)$ & "thankful," "it must be working," "don't be afraid" \\
\hline So-so & $8(15.0)$ & $\begin{array}{l}\text { "hope it helps," "minimal risk," "might work," \#BeWarnedBeWell, "it might fight } \\
\text { COVID-19," "take care world!" "interesting to see" }\end{array}$ \\
\hline Bad & $6(11.0)$ & $\begin{array}{l}\text { \#plaquenilshortage," "no tests will be done for } 2 \text { months," "facing shortages," "no } \\
\text { proof \#Hydroxychloroquine makes us safe"" }\end{array}$ \\
\hline Wretched & $28(51.0)$ & 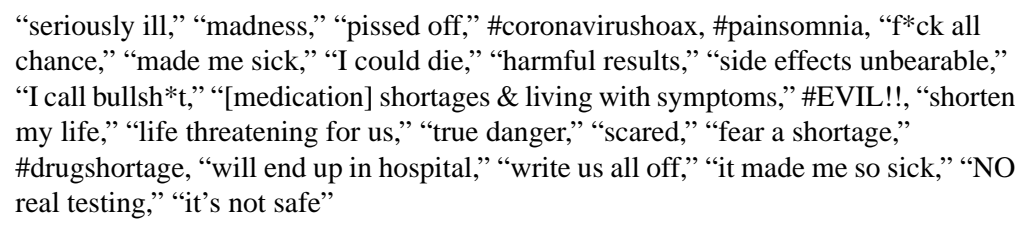 \\
\hline No sentiment & $5(9.0)$ & $\begin{array}{l}\text { "research says," "UK government wants," "prove hypothesis," "IL-6 is raised," "from } \\
\text { the CDC" }\end{array}$ \\
\hline Personal stories & $29(20.0)$ & \\
\hline Great & $5(17.0)$ & $\begin{array}{l}\text { "all good during this \#covid19," "it makes me feel better on a personal level," "bring } \\
\text { it on world," "I am a champion!" \#livingmybestlife }\end{array}$ \\
\hline Swell & $5(17.0)$ & \#AloneTogether, \#nevergiveup, \#hope, \#makethebestofit, "trying to keep active" \\
\hline So-so & $3(10.0)$ & "it is what it is," "I hope they have a lot of masks and sanitizer!" \\
\hline Bad & $2(7.5)$ & "I didn't want to risk heading out," "limiting my usual walk" \\
\hline Wretched & $12(41.0)$ & $\begin{array}{l}\text { "give us a break, FFS!" \#HighRiskCovid19, "I hate \#Coronavirus," "literally a pain," } \\
\text { "holy sh*t," "screaming into the void," "I am not \#expendable," "being told to go to } \\
\text { a germy hospital," "my chances of surviving \#covid19 are horrible," "vulnerable pa- } \\
\text { tients like me" }\end{array}$ \\
\hline No sentiment & $2(7.5)$ & "info is changing daily," "I'm immunocompromised because" \\
\hline $\begin{array}{l}\text { Links to or advertisements of relevant } \\
\text { blogs and forums }\end{array}$ & $22(14.0)$ & \\
\hline Great & $1(5.0)$ & "so grateful" \\
\hline Swell & $2(9.0)$ & "talking about work/life balance," "we are here for you" \\
\hline So-so & $4(18.0)$ & "coping in isolation," "trying to deal," "hoping to support others" \\
\hline $\mathrm{Bad}$ & $2(9.0)$ & "how to handle flares," "learn what's happening to people with arthritis" \\
\hline Wretched & $4(18.0)$ & $\begin{array}{l}\text { "covid19 scariness," "fear of dying," "unpredictability and fear," "we worry about } \\
\text { everyone" }\end{array}$ \\
\hline No sentiment & $9(41.0)$ & $\begin{array}{l}\text { "video games during covid19," "questions I have," "share with your networks," } \\
\text { "breaking news," "please consider sharing," "please retweet," "I found this information" }\end{array}$ \\
\hline Discussion of arthritis-related symptoms & $15(10.0)$ & \\
\hline Great & $0(0.0)$ & $-\mathrm{b}$ \\
\hline Swell & $0(0.0)$ & - \\
\hline So-so & $1(7.0)$ & "not the end of the world" \\
\hline $\mathrm{Bad}$ & $1(7.0)$ & "I have to take a break" \\
\hline Wretched & $13(86.0)$ & $\begin{array}{l}\text { "struggling to sleep/be active," "spoonie fail," "the arthritis flared out of control," "my } \\
\text { shoulder is a casualty," "pain in the knees," "I'm screwed," "ouchy grouchy," "feet } \\
\text { are burning," "f*'*k you coronavirus," "worsening arthritis pain," "I'm already achy," } \\
\text { "flaring due to extra phone use" }\end{array}$ \\
\hline No sentiment & $0(0.0)$ & - \\
\hline Advice seeking & $14(9.0)$ & \\
\hline Great & $0(0.0)$ & - \\
\hline
\end{tabular}




\begin{tabular}{|c|c|c|}
\hline Original theme and sentiment ${ }^{\mathrm{a}}$ & Tweets, n (\%) & Examples of phrases or \#hashtags \\
\hline Swell & $1(7.0)$ & "thanks to the doctors for their expertise" \\
\hline So-so & $0(0.0)$ & - \\
\hline Bad & $1(7.0)$ & "some chance of developing complications" \\
\hline Wretched & $8(57)$ & $\begin{array}{l}\text { "lowered immunity more than it already is," "significantly increase risk of infection," } \\
\text { "things have been rough," "zero immune system," "so stressed about \#coronavirus," } \\
\text { "no money for food let alone masks," "I'm disabled" }\end{array}$ \\
\hline No sentiment & $4(29.0)$ & $\begin{array}{l}\text { "grateful for info," "where can I volunteer to get tested," \#lockdownUK, "would ap- } \\
\text { preciate a video of exercises for in \#lockdown" }\end{array}$ \\
\hline Messages of positivity & $8(6.0)$ & \\
\hline Great & $2(25.0)$ & $\begin{array}{l}\text { "coronavirus caused some good things to happen," "amazing how motivating boredom } \\
\text { is" }\end{array}$ \\
\hline Swell & $3(37.5)$ & \#selfmanagement, "right exercises to keep arthritis at bay," "enjoy the little things" \\
\hline So-so & $1(12.5)$ & "life is too short to be scared" \\
\hline Bad & $1(12.5)$ & "keeping positive a challenge" \\
\hline Wretched & $0(0.0)$ & - \\
\hline No sentiment & $1(12.5)$ & "this information might help" \\
\hline Stay-at home-messaging & $6(4.0)$ & \\
\hline Great & $0(0.0)$ & - \\
\hline Swell & $0(0.0)$ & - \\
\hline So-so & $0(0.0)$ & - \\
\hline $\mathrm{Bad}$ & $0(0.0)$ & - \\
\hline Wretched & $5(83.0)$ & $\begin{array}{l}\text { "\#selfisolation only because of my immune system," \#arthritissucks so stay the f*ck } \\
\text { home," "coronavirus could kill me \#StayHomeSaveLives," "\#PLEASESTAYHOME } \\
\text { I'm devastated," "arthritis shot to sh*t stay home" }\end{array}$ \\
\hline No sentiment & $1(17.0)$ & \#GoHomeStayHome \\
\hline
\end{tabular}

${ }^{\mathrm{a}}$ Great: the tweet is purely positive; swell: the tweet contains mainly positive phrases and words that outweigh negative sentiment; so-so: the tweet has a mediocre and balanced sentiment where positive and negative statements are balanced; bad: the tweet contains mainly negative phrases and words that outweigh any positive sentiment; wretched: the tweet is purely negative; no sentiment: the tweet has no emotion or words or special punctuation and is matter-of-fact sounding.

${ }^{b}$ Not available.

A few tweets contained messages of positivity. While overall "keeping positive [was] a challenge," some people encouraged others to "enjoy the little things" and that "life is too short to be scared." Still, the extent to which people with arthritis were concerned for their health was evident in people's stay-at-home messaging. Tweeters were notably anxious and angry, writing that "\#arthritissucks so stay the f*ck home," that "coronavirus could kill me \#StayHomeSaveLives," and “\#PLEASESTAYHOME I'm devastated."

Using Glaser and Strauss's [28] classifications, more than half of the tweets contained wretched (purely negative) or bad (mainly negative) sentiment $(n=83,56 \%)$, whereas only one-fifth of tweets contained great (purely positive) or swell (mainly positive) sentiment $(\mathrm{n}=27,18 \%)$. In total, $16(11 \%)$ tweets contained sentiment that was so-so (balanced negativity and positivity), and $22(15 \%)$ tweets contained no sentiment (matter-of-fact sounding).

Individuals in the United States appeared particularly despondent regarding their health care experiences during the COVID-19 pandemic. When referencing interactions with the health care system, tweets contained phrases such as "true danger," "seriously pissed off," and "scared." Tweeters noted "it's not safe" for people with arthritis facing hydroxychloroquine shortages, and that the \#drugshortage was "life threatening." Some individuals mused that there is "minimal risk" trying hydroxychloroquine to cure COVID-19, and that it might be "interesting to see" the results of this medication. Outside of the United States, Canadians tweeted that engaging with the health care system during the pandemic was a "doddle" and that they were "thankful" to continue to have access to their health professionals.

Many individuals described their personal stories negatively. People with arthritis discussed barriers to accessing care, such as being surprised at "being told to go to a germy hospital" and that they "didn't want to risk going out." Tweets with links to blogs were accompanied by captions "fear of dying," "unpredictability and fear," and "we worry about everyone." Some were more positive, encouraging followers that they are "hoping to support others." Although their representation was small, people with arthritis in Ireland and New Zealand viewed 
the isolation measures as an opportunity for \#hope, encouraging others to \#makethebestofit and to \#nevergiveup.

A consistent sentiment was that people with arthritis were negative in their discussion of physical and psychological symptoms, with many individuals seeking advice from peers and health professionals to remedy symptoms. Tweets highlighted the spectrum of symptoms that individuals experienced during the pandemic, with people "struggling to sleep/be active," experiencing "worsening arthritis pain," and having "pain in the knees." Some noted that attempting to manage physical symptoms while in isolation was "literally a pain" and that the psychological toll was like "screaming into the void." One tweeter mentioned that their arthritis was "flaring due to extra phone use," which was frustrating since this was a primary method of maintaining social connection and communication with family or colleagues during the pandemic. Similarly, individuals tweeting and asking for advice did so by prefacing that "things have been rough," that they have "zero immune system," and that they are "so stressed about \#coronavirus."

Our sentiment analysis included an overview of emoji use in tweets, as summarized in Table 5. 
Table 5. Sentiment analysis of emoji use in tweets.

\begin{tabular}{|c|c|c|c|c|c|}
\hline Emoji $^{\mathrm{a}}$ & Count, $\mathrm{n}$ & Emoji name & $\begin{array}{l}\text { Phrases or \#hashtags accompanying } \\
\text { the emoji }\end{array}$ & Emotion & Link to original themes \\
\hline & 3 & $\begin{array}{l}\text { Face with no good } \\
\text { gesture }\end{array}$ & $\begin{array}{l}\text { "my feet are burning," things are very } \\
\text { painful," "my chances of surviving are } \\
\text { horrible", }\end{array}$ & Negative & $\begin{array}{l}\text { Discussion of arthritis-related symptoms, } \\
\text { personal stories }\end{array}$ \\
\hline & 2 & Clapping hands sign & $\begin{array}{l}\text { "my team have worked so hard," } \\
\text { "massive thanks" }\end{array}$ & Positive & $\begin{array}{l}\text { Links to or advertisements of relevant blogs } \\
\text { and forums, advice seeking }\end{array}$ \\
\hline & 2 & $\begin{array}{l}\text { Smiling face with } \\
\text { smiley eyes }\end{array}$ & "hope it helps all" & Positive & Health care experiences \\
\hline & 2 & Confused face & $\begin{array}{l}\text { "I might be screwed," "I think my } \\
\text { consultant is wrong", }\end{array}$ & Negative & $\begin{array}{l}\text { Health care experiences, discussion of } \\
\text { arthritis-related symptoms }\end{array}$ \\
\hline & 2 & $\begin{array}{l}\text { Person with folded } \\
\text { hands }\end{array}$ & \#lupuswarrior & Positive & Personal stories, health care experiences \\
\hline & 2 & Red heart suit & "hoping to support others," \#BeSafe & Positive & $\begin{array}{l}\text { Links to or advertisements of relevant blogs } \\
\text { and forums }\end{array}$ \\
\hline & 2 & Purple heart & "choose to spread awareness" & Positive & Personal stories \\
\hline & 1 & Crying face & “\#coronavirus has opened my eyes" & Neutral & Health care experiences \\
\hline & 1 & Smirking face & “\#makingthebestofit & Positive & Personal stories \\
\hline & 1 & Fisted hand sign & "I've got a morphine patch on to help" & Positive & Personal stories \\
\hline & 1 & $\begin{array}{l}\text { Face with tears of } \\
\text { joy }\end{array}$ & "happy sitting in the sun" & Positive & Messages of positivity \\
\hline & 1 & $\begin{array}{l}\text { Leaves fluttering in } \\
\text { the wind }\end{array}$ & "I'm laying outside" & Positive & Personal stories \\
\hline & 1 & $\begin{array}{l}\text { Face with mouth } \\
\text { open }\end{array}$ & $\begin{array}{l}\text { "could potentially lead to the cure for } \\
\text { \#Coronavirus" }\end{array}$ & Positive & Health care experiences \\
\hline & 1 & Winking face & $\begin{array}{l}\text { "I made healthy Easter treats in self is- } \\
\text { lation" }\end{array}$ & Positive & Personal stories \\
\hline & 1 & Pill & "I really miss anti-inflammatories" & Negative & Stay-at-home messaging \\
\hline & 1 & $\begin{array}{l}\text { Front-facing baby } \\
\text { chick }\end{array}$ & \#livingmybestlife & Positive & Personal stories \\
\hline
\end{tabular}




\begin{tabular}{|c|c|c|c|c|c|}
\hline Emoji $^{\mathrm{a}}$ & Count, $\mathrm{n}$ & Emoji name & $\begin{array}{l}\text { Phrases or \#hashtags accompanying } \\
\text { the emoji }\end{array}$ & Emotion & Link to original themes \\
\hline 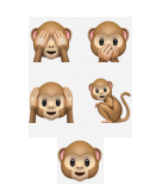 & 1 each & $\begin{array}{l}\text { See-no-evil monkey, } \\
\text { speak-no-evil mon- } \\
\text { key, hear-no-evil } \\
\text { monkey, monkey, } \\
\text { monkey face }\end{array}$ & $\begin{array}{l}\text { "my rheumatologist said I wasn't at } \\
\text { high risk" }\end{array}$ & Positive & Health care experiences \\
\hline
\end{tabular}

${ }^{a}$ Emoji Sentiment Ranking did not include the upside-down face, the spectacle face, or the high-five emoji. There was one of each included in our data collection.

The emoji within tweets established tone and emphasized emotions. Most tweets used an emoji to express positive sentiment, such as clapping hands to thank colleagues for their support and a person with folded hands in acknowledgment of the personal commitment to the ongoing management of arthritis symptoms in isolation. The main emoji used to express negative sentiment were the face with "no good" gesture, and the confused face. Tweeters used the face with "no good" gesture to highlight their physical pain, and the confused face was used to express confusion around what arthritis patients perceived to be ill-informed health advice during the pandemic.

\section{Discussion}

\section{Principal Findings}

This study aimed to identify proxy topics of importance for people with arthritis during COVID-19 by characterizing the textual content and sentiment of tweets, and exploring the emotional context of tweets by people with arthritis during the early phase of the pandemic. We anticipated that this novel approach would ascertain contemporary topics of importance for immunocompromised and isolated individuals. Content analysis revealed seven themes relating to health care experiences, and sentiment analysis revealed that the majority of tweets contained negative emotion, particularly around medication shortages, increased arthritis symptoms, and the physical and mental toll of physical distancing or living in isolation. Our findings provide a starting point for understanding the impacts of COVID-19 on vulnerable arthritis populations and provide some insights for physicians and researchers regarding current concerns that may inform tailored care.

More than one-third of tweets discussed health care experiences, primarily focusing on the reduced availability of hydroxychloroquine. Individuals were highly anxious about hydroxychloroquine shortages after preliminary research found that the drug might act as a potential preventive measure, or possible cure, for COVID-19 and these early findings were highly publicized around the world. The original published article has since been retracted after researchers were unable to verify the reliability of their results [33]. Regardless, President Trump tweeted his support for hydroxychloroquine as "one of the biggest game changers in the history of medicine" [34], causing panic about medication shortages, particularly from those with systemic lupus erythematosus for which it is the first-line therapy [35]. Due to off-label prescriptions and hoarding practices, difficulties accessing hydroxychloroquine have been reported globally [36]. Hydroxychloroquine shortages pose a threat to the health and safety of people with inflammatory arthritis, with reports that many will experience flare-ups and may develop irreversible organ damage without their regular dose [35]. Our findings highlight the need for accurate information about treatments and their effectiveness and the critical role that clinicians play in dispelling myths and inaccuracies during times of rapidly changing information. A growing body of literature describes the potential benefits of using Twitter in clinical settings, and reports ways that clinicians are using platforms such as Twitter to communicate health information to the broader population [37-39]. In the context of infectious diseases in particular, evidence suggests that Twitter is beneficial to translate real-time clinical information $[40,41]$. Use of Twitter, being a component of mobile health (mHealth), also empowers patients to more positively perceive their abilities to manage chronic illness [42]. This presents an opportunity for clinicians and professional societies to use social media platforms such as Twitter to overcome evidence dissemination methods (eg, peer-reviewed articles and care guidelines) that are traditionally slow. Together, clinicians and patients can contribute to care in adults with arthritis, encouraging positive health outcomes throughout, and beyond, the pandemic.

Several tweets contained very personal narratives that highlighted individual fears of contracting COVID-19, and the challenges associated with being vulnerable to infection. Individuals described perceived barriers to accessing care, citing discomfort caused by wearing medical-grade personal protective equipment. Tweets contained accounts of neck pain attributed to wearing a mask; a documented side effect in other vulnerable populations [43]. Fitting a mask is also a dexterous task that some people with arthritis struggled to perform, and as a result, encountered abuse from others when buying groceries or going for a walk. The long-term psychosocial impact of this stigma should receive consideration in future research. Clinicians should consider COVID-19-related functional concerns for physically impaired patients, and incorporate new aspects of information-seeking into clinical consultations. For example, asking patients about their degree of difficulty with COVID-19-related functional tasks would help to elicit relevant functional challenges faced by people with arthritis and inform the provision of tailored patient education. Asking these questions also contributes to factors beyond patient education and care, such as facilitating access to nonacute symptom or pain management services such as allied health. These health services still need to be maintained during and after the pandemic, and for musculoskeletal health in particular, there is emerging commentary around the physical and psychosocial impacts of inhibited access $[44,45]$. 
Tweets detailed marked increases in general physical symptom burden; a concerning prospect as COVID-19 has impacted face to face consultations, with indications that disruptions to traditional service models will likely persist for some time. Evidence about the utility of telemedicine to manage pain is emerging, with consideration of barriers to implementation, and potential inequity in access [46], although health systems have been generally slow to implement this approach at scale. While the included tweets provide preliminary information about the growing symptom burden during the pandemic, the collection of systematic patient-reported outcomes data is needed to ensure that health care services are meeting the needs of people with arthritis during and after the COVID-19 pandemic.

A proportion of tweets related to social connection, that is, people reaching out to likeminded peers with arthritis through potentially informative blogs. Most links provided were to official (eg, CreakyJoints) or unofficial (eg, online communities and forums) blogs and provided information on how to manage physical and mental health in isolation, a range of arthritis-appropriate exercises, and existing evidence on the association between arthritis and risk of COVID-19 infection. Access to resources that are relevant, credible, and trustworthy appears to have been challenging for people with arthritis throughout the pandemic [47], and combined with high levels of misinformation online $[48,49]$, this may account for the recent growth of platforms such as Twitter for sourcing information and advice.

Before the COVID-19 pandemic, people with arthritis primarily used social media for self-expression and positive messaging [50,51]. Our sentiment analysis (enhanced by classifying emojis to further characterize common emotions) demonstrates that the role of Twitter has evolved throughout the current pandemic to act as a space for people to share symptoms; to reach out to peers, organizations, and health professionals for information; and to create a sympathetic community of care. This is advantageous as it fosters connection between individuals with shared experiences but conversely may enable proliferation of misinformation [52]. Already, Twitter has been shown to inform clinical practice by capturing the experiences of patients with multiple sclerosis during the pandemic [53]. Understanding the COVID-19-related concerns of people with arthritis is also key to providing person-centered care and reducing distress during these rapidly changing times.

\section{Strengths and Limitations}

The observational exploratory nature of this study enabled us to examine topics of importance for individuals with arthritis through a person-centered lens, without ethical issues or compromising the well-being of immunocompromised patients during the pandemic. Social media research is still in its infancy, and this novel method of data collection demonstrates the concerns of people with arthritis during a time of peak anxiety.
There is some indication that tweeters were representative of the general inflammatory arthritis population; the majority were female and the most common arthritis type identified was rheumatoid arthritis. Nearly half (44.0\%) of tweeters were based in the United States, which currently leads the world in COVID-19 cases and deaths [54].

We also acknowledge the research limitations. It is important to note that only $15 \%$ of adults regularly use Twitter, and that younger adults and minority communities tend to be more highly represented on Twitter than the general population [55], although minority communities have been significantly impacted by COVID-19 [56,57]. Our results should therefore be interpreted as representing a small subset of people with arthritis, and not all people with the disease. Data were extracted rather than collected directly from people with arthritis and critics of social media research purport that posts or tweets are often curated and may not be reflective of reality. We have attempted to minimize this potential bias by conducting sentiment analysis, which helped us determine the emotional tone associated with Twitter content. Regardless, sentiment analysis has its limitations: populations and individuals are constantly stimulated by their political and socioeconomic surroundings and individual demographics, which can influence the content and sentiment of people's tweets $[58,59]$. We also recognize the potential limitations of our search strategy (eg, we did not search for hashtags related to specific symptoms, such as pain or function, that are not unique to arthritis) that may have impacted the number of retrieved tweets. While we had a modest sample size of tweets due to our focused study aims, sentiment analysis has previously been conducted in studies with comparable sample sizes of tweets $(n=260$ and $n=200)[60,61]$. We were unable to determine the specific diagnostic category for over half the people tweeting; while a small number of tweets were from people with osteoarthritis, it is possible that more may be represented within the "diagnosis not specified" category. We were only able to analyze tweets in English, and these largely came from high-income, developed countries. Tweets in other languages and those from people in low-and-middle income countries may provide further insights, especially where the prevalence of COVID-19 infection is high [62].

\section{Conclusion}

This study highlights the spectrum of concerns facing people with arthritis during the COVID-19 pandemic. By exploring the content and sentiment of recent tweets, we found that individuals with arthritis conditions experience marked anxiety about medication shortages and increased physical symptom burden, and are seeking connection with and information from peers. These findings can be used to raise awareness of key issues relevant to people with arthritis during the pandemic, and to guide clinicians to tailor care that addresses the specific concerns and needs of their patients during the pandemic.

\section{Acknowledgments}

DB received a $\mathrm{PhD}$ scholarship from Musculoskeletal Australia to conduct this research [PURE ID \#230581862]. INA is supported by a Victorian Health and Medical Research Fellowship from the Victorian Government. 


\section{Conflicts of Interest}

None declared.

\section{Multimedia Appendix 1}

Twitter search strategy and results.

[DOCX File, 15 KB-Multimedia Appendix 1]

\section{References}

1. Hamm MP, Chisholm A, Shulhan J, Milne A, Scott SD, Given LM, et al. Social media use among patients and caregivers: a scoping review. BMJ Open 2013 May 09;3(5):e002819 [FREE Full text] [doi: 10.1136/bmjopen-2013-002819] [Medline: 23667163]

2. Zhao Y, Zhang J. Consumer health information seeking in social media: a literature review. Health Info Libr J 2017 Dec 17;34(4):268-283. [doi: 10.1111/hir.12192] [Medline: 29045011]

3. Merolli M, Gray K, Martin-Sanchez F. Health outcomes and related effects of using social media in chronic disease management: a literature review and analysis of affordances. J Biomed Inform 2013 Dec;46(6):957-969 [FREE Full text] [doi: 10.1016/j.jbi.2013.04.010] [Medline: 23702104]

4. Santoro E, Castelnuovo G, Zoppis I, Mauri G, Sicurello F. Social media and mobile applications in chronic disease prevention and management. Front Psychol 2015 May 07;6:567 [FREE Full text] [doi: 10.3389/fpsyg.2015.00567] [Medline: 25999884]

5. Eriksson M, Olsson E. Facebook and Twitter in Crisis Communication: A Comparative Study of Crisis Communication Professionals and Citizens. J Contingencies \& Crisis Man 2016 Jun 13;24(4):198-208. [doi: 10.1111/1468-5973.12116]

6. Curtis JR, Chen L, Higginbotham P, Nowell WB, Gal-Levy R, Willig J, et al. Social media for arthritis-related comparative effectiveness and safety research and the impact of direct-to-consumer advertising. Arthritis Res Ther 2017 Mar 07;19(1):48 [FREE Full text] [doi: 10.1186/s13075-017-1251-y] [Medline: 28270190]

7. Kloth YM, Deutsch KM, Danielson KA, Strack J, Law C. What Twitter teaches us about patient-provider communication on pain. PLoS One 2019 Dec 26;14(12):e0226321 [FREE Full text] [doi: 10.1371/journal.pone.0226321] [Medline:

31877158]

8. Caporali R, Caprioli M, Bobbio-Pallavicini F, Montecucco C. DMARDS and infections in rheumatoid arthritis. Autoimmun Rev 2008 Dec;8(2):139-143. [doi: 10.1016/j.autrev.2008.05.001] [Medline: 19014871]

9. Coronavirus (COVID-19) advice for people with chronic conditions. Australian Government. 2020. URL: https://www. health.gov.au/news/health-alerts/novel-coronavirus-2019-ncov-health-alert/advice-for-people-at-risk-of-coronavirus-covid-19/ coronavirus-covid-19-advice-for-people-with-chronic-health-conditions [accessed 2020-09-10]

10. Fredi M, Cavazzana I, Moschetti L, Andreoli L, Franceschini F, Airò P, et al. COVID-19 in patients with rheumatic diseases in northern Italy: a single-centre observational and case-control study. The Lancet Rheumatology 2020 Sep;2(9):e549-e556. [doi: 10.1016/s2665-9913(20)30169-7]

11. Zhong J, Shen G, Yang H, Huang A, Chen X, Dong L, et al. COVID-19 in patients with rheumatic disease in Hubei province, China: a multicentre retrospective observational study. The Lancet Rheumatology 2020 Sep;2(9):e557-e564. [doi:

10.1016/s2665-9913(20)30227-7]

12. Gianfrancesco M, Hyrich KL, Al-Adely S, Carmona L, Danila MI, Gossec L, COVID-19 Global Rheumatology Alliance. Characteristics associated with hospitalisation for COVID-19 in people with rheumatic disease: data from the COVID-19 Global Rheumatology Alliance physician-reported registry. Ann Rheum Dis 2020 Jul 12;79(7):859-866 [FREE Full text] [doi: 10.1136/annrheumdis-2020-217871] [Medline: 32471903]

13. UPDATED: Advice regarding Coronavirus (COVID-19) from the Australian Rheumatology Association. Arthritis Australia. 2020. URL: https://arthritisaustralia.com.au/ advice-regarding-coronavirus-covid-19-from-the-australian-rheumatology-association/ [accessed 2020-09-10]

14. Décary S, Barton JL, Proulx L, Richards DP, Paterson G, de Wit M, et al. How to Effectively Support Patients with Rheumatic Conditions Now and Beyond COVID-19. ACR Open Rheumatol 2020 Sep 28;2(9):505-506 [FREE Full text] [doi: 10.1002/acr2.11152] [Medline: 32403182]

15. Michaud K, Wipfler K, Shaw Y, Simon TA, Cornish A, England BR, et al. Experiences of Patients With Rheumatic Diseases in the United States During Early Days of the COVID-19 Pandemic. ACR Open Rheumatol 2020 Jun 09;2(6):335-343 [FREE Full text] [doi: $10.1002 /$ acr2.11148] [Medline: $\underline{\text { 32311836] }}$

16. Mobasheri A. COVID-19, osteoarthritis and women's health. Case Reports in Women's Health 2020 Jul;27:e00207. [doi: 10.1016/j.crwh.2020.e00207]

17. Gadde V, Derella M. An update on our continuity strategy during COVID-19. Twitter. 2020. URL: https://blog.twitter.com/ en us/topics/company/2020/An-update-on-our-continuity-strategy-during-COVID-19.html [accessed 2020-09-10]

18. Terms of Service. Twitter. 2020. URL: https://twitter.com/en/tos [accessed 2020-09-10]

19. Advanced search function [image]. Twitter. URL: https://twitter.com/search-advanced?lang=en [accessed 2020-09-10]

20. Staying at home and away from others (social distancing). Gov.UK. 2020. URL: https://www.gov.uk/government/publications/ full-guidance-on-staying-at-home-and-away-from-others [accessed 2020-09-10] 
21. Update on Coronavirus Measures. Prime Minister of Australia. 2020. URL: https://www.pm.gov.au/media/ update-coronavirus-measures-24-March-2020 [accessed 2020-09-10]

22. Vinceti M, Filippini T, Rothman KJ, Ferrari F, Goffi A, Maffeis G, et al. Lockdown timing and efficacy in controlling COVID-19 using mobile phone tracking. EClinicalMedicine 2020 Aug;25:100457 [FREE Full text] [doi: 10.1016/j.eclinm.2020.100457] [Medline: 32838234]

23. Zhang R, Li Y, Zhang AL, Wang Y, Molina MJ. Identifying airborne transmission as the dominant route for the spread of COVID-19. Proc Natl Acad Sci U S A 2020 Jun 30;117(26):14857-14863 [FREE Full text] [doi: 10.1073/pnas.2009637117] [Medline: 32527856]

24. Vaismoradi M, Turunen H, Bondas T. Content analysis and thematic analysis: Implications for conducting a qualitative descriptive study. Nurs Health Sci 2013 Sep 11;15(3):398-405. [doi: 10.1111/nhs.12048] [Medline: 23480423]

25. Hsieh H, Shannon SE. Three approaches to qualitative content analysis. Qual Health Res 2005 Nov;15(9):1277-1288. [doi: 10.1177/1049732305276687] [Medline: 16204405]

26. Briggs A, Houlding E, Hinman R, Desmond L, Bennell K, Darlow B, et al. Health professionals and students encounter multi-level barriers to implementing high-value osteoarthritis care: a multi-national study. Osteoarthritis Cartilage 2019 May;27(5):788-804. [doi: 10.1016/j.joca.2018.12.024] [Medline: 30668988]

27. Greaves F, Ramirez-Cano D, Millett C, Darzi A, Donaldson L. Use of sentiment analysis for capturing patient experience from free-text comments posted online. J Med Internet Res 2013 Nov 01;15(11):e239 [FREE Full text] [doi:

10.2196/jmir.2721] [Medline: 24184993]

28. Glaser B, Strauss A. The Discovery of Grounded Theory: Strategies for Qualitative Research. London and New York: Routledge Taylor \& Francis Group; 1967.

29. Jansen BJ, Zhang M, Sobel K, Chowdury A. Twitter power: Tweets as electronic word of mouth. J Am Soc Inf Sci 2009 Nov;60(11):2169-2188. [doi: 10.1002/asi.21149]

30. Williams SA, Terras MM, Warwick C. What do people study when they study Twitter? Classifying Twitter related academic papers. Journal of Documentation 2013 May 10;69(3):384-410. [doi: 10.1108/jd-03-2012-0027]

31. Kralj Novak P, Smailović J, Sluban B, Mozetič I. Sentiment of Emojis. PLoS One 2015 Dec 7;10(12):e0144296 [FREE Full text] [doi: 10.1371/journal.pone.0144296] [Medline: 26641093]

32. Ayers JW, Caputi TL, Nebeker C, Dredze M. Don't quote me: reverse identification of research participants in social media studies. NPJ Digit Med 2018 Aug 2;1(1):30 [FREE Full text] [doi: 10.1038/s41746-018-0036-2] [Medline: 31304312]

33. Mehra MR, Desai SS, Ruschitzka F, Patel AN. RETRACTED: Hydroxychloroquine or chloroquine with or without a macrolide for treatment of COVID-19: a multinational registry analysis. The Lancet 2020 May. [doi: 10.1016/s0140-6736(20)31180-6]

34. @ realDonaldTrump. Twitter. 2020 Mar 22. URL: https://twitter.com/realDonaldTrump/status/1241367239900778501 [accessed 2020-09-10]

35. Mehta B, Salmon J, Ibrahim S. Potential Shortages of Hydroxychloroquine for Patients with Lupus During the Coronavirus Disease 2019 Pandemic. JAMA Health Forum 2020 Apr 10;1(4):e200438. [doi: 10.1001/jamahealthforum.2020.0438]

36. Choo EK, Rajkumar SV. Medication Shortages During the COVID-19 Crisis: What We Must Do. Mayo Clin Proc 2020 Jun;95(6):1112-1115 [FREE Full text] [doi: 10.1016/j.mayocp.2020.04.001] [Medline: 32312491]

37. Pershad Y, Hangge P, Albadawi H, Oklu R. Social Medicine: Twitter in Healthcare. J Clin Med 2018 May 28;7(6):121 [FREE Full text] [doi: 10.3390/jcm7060121] [Medline: 29843360]

38. Hawn C. Take Two Aspirin And Tweet Me In The Morning: How Twitter, Facebook, And Other Social Media Are Reshaping Health Care. Health Affairs 2009 Mar;28(2):361-368. [doi: 10.1377/hlthaff.28.2.361]

39. Cifu AS, Vandross AL, Prasad V. Case Reports in the Age of Twitter. Am J Med 2019 Oct;132(10):e725-e726. [doi: 10.1016/j.amjmed.2019.03.044] [Medline: 30998916]

40. Goff DA, Kullar R, Newland JG. Review of Twitter for infectious diseases clinicians: useful or a waste of time? Clin Infect Dis 2015 May 15;60(10):1533-1540. [doi: 10.1093/cid/civ071] [Medline: 25652087]

41. Ghosh P, Schwartz G, Narouze S. Twitter as a powerful tool for communication between pain physicians during COVID-19 pandemic. Reg Anesth Pain Med 2020 Apr 21. [doi: 10.1136/rapm-2020-101530] [Medline: 32321859]

42. Slater H, Campbell JM, Stinson JN, Burley MM, Briggs AM. End User and Implementer Experiences of mHealth Technologies for Noncommunicable Chronic Disease Management in Young Adults: Systematic Review. J Med Internet Res 2017 Dec 12;19(12):e406 [FREE Full text] [doi: 10.2196/jmir.8888] [Medline: 29233804]

43. Ong JJ, Bharatendu C, Goh Y, Tang JZ, Sooi KW, Tan YL, et al. Headaches Associated With Personal Protective Equipment - A Cross-Sectional Study Among Frontline Healthcare Workers During COVID-19. Headache 2020 May 12;60(5):864-877. [doi: 10.1111/head.13811] [Medline: $\underline{\text { 32232837] }}$

44. Karos K, McParland JL, Bunzli S, Devan H, Hirsh A, Kapos FP, et al. The social threats of COVID-19 for people with chronic pain. Pain 2020 Oct 13;161(10):2229-2235 [FREE Full text] [doi: 10.1097/j.pain.0000000000002004] [Medline: $\underline{32694381]}$

45. Nestola T, Orlandini L, Beard JR, Cesari M. COVID-19 and Intrinsic Capacity. J Nutr Health Aging 2020 May 28;24(7):692-695. [doi: 10.1007/s12603-020-1397-1] [Medline: 32744562] 
46. Eccleston C, Blyth FM, Dear BF, Fisher EA, Keefe FJ, Lynch ME, et al. Managing patients with chronic pain during the COVID-19 outbreak: considerations for the rapid introduction of remotely supported (eHealth) pain management services. Pain 2020 May;161(5):889-893 [FREE Full text] [doi: 10.1097/j.pain.0000000000001885] [Medline: 32251203]

47. Duron G, Gelman L, Dua A, Putman M. Tracking clinical resources for coronavirus disease 2019. Curr Opin Rheumatol 2020 Sep;32(5):441-448. [doi: 10.1097/BOR.0000000000000724] [Medline: 32675716]

48. Li HO, Bailey A, Huynh D, Chan J. YouTube as a source of information on COVID-19: a pandemic of misinformation? BMJ Glob Health 2020 May 14;5(5):e002604 [FREE Full text] [doi: 10.1136/bmjgh-2020-002604] [Medline: 32409327]

49. Erku DA, Belachew SA, Abrha S, Sinnollareddy M, Thomas J, Steadman KJ, et al. When fear and misinformation go viral: Pharmacists' role in deterring medication misinformation during the 'infodemic' surrounding COVID-19. Res Social Adm Pharm 2020 May 01 [FREE Full text] [doi: 10.1016/j.sapharm.2020.04.032] [Medline: 32387230]

50. Modica R, Lomax KG, Batzel P, Cassanas A. OARRR 2018 Jun;Volume 10:73-81. [doi: 10.2147/oarrr.s165010]

51. des Bordes JKA, Foreman J, Westrich-Robertson T, Lopez-Olivo MA, Peterson SK, Hofstetter C, et al. Interactions and perceptions of patients with rheumatoid arthritis participating in an online support group. Clin Rheumatol 2020 Jun 31;39(6):1775-1782. [doi: 10.1007/s10067-020-04967-y] [Medline: 32006180]

52. Malecki K, Keating J, Safdar N. Crisis Communication and Public Perception of COVID-19 Risk in the Era of Social Media. Clin Infect Dis 2020 Jun 16:2020 [FREE Full text] [doi: 10.1093/cid/ciaa758] [Medline: 32544242]

53. Nesbitt C, Rath L, Yeh WZ, Zhong M, Wesselingh R, Monif M, et al. MSCOVID19: Using social media to achieve rapid dissemination of health information. Mult Scler Relat Disord 2020 Oct;45:102338. [doi: 10.1016/j.msard.2020.102338] [Medline: 32629402]

54. Schneider EC. Failing the Test - The Tragic Data Gap Undermining the U.S. Pandemic Response. N Engl J Med 2020 Jul 23;383(4):299-302. [doi: 10.1056/nejmp2014836]

55. Smith A, Brenner R. Twitter Use 2012. Pew Research Center Internet \& Technology. 2012 May 31. URL: https://www. pewresearch.org/internet/2012/05/31/twitter-use-2012/ [accessed 2020-09-10]

56. Clark E, Fredricks K, Woc-Colburn L, Bottazzi ME, Weatherhead J. Disproportionate impact of the COVID-19 pandemic on immigrant communities in the United States. PLoS Negl Trop Dis 2020 Jul 13;14(7):e0008484 [FREE Full text] [doi: 10.1371/journal.pntd.0008484] [Medline: $\underline{32658925]}$

57. Pan D, Sze S, Minhas JS, Bangash MN, Pareek N, Divall P, et al. The impact of ethnicity on clinical outcomes in COVID-19: A systematic review. EClinicalMedicine 2020 Jun;23:100404 [FREE Full text] [doi: 10.1016/j.eclinm.2020.100404] [Medline: $\underline{32632416]}$

58. Padilla JJ, Kavak H, Lynch CJ, Gore RJ, Diallo SY. Temporal and spatiotemporal investigation of tourist attraction visit sentiment on Twitter. PLoS One 2018 Jun 14;13(6):e0198857 [FREE Full text] [doi: 10.1371/journal.pone.0198857] [Medline: 29902270]

59. Gore RJ, Diallo S, Padilla J. You Are What You Tweet: Connecting the Geographic Variation in America's Obesity Rate to Twitter Content. PLoS One 2015 Sep 2;10(9):e0133505 [FREE Full text] [doi: 10.1371/journal.pone.0133505] [Medline: 26332588]

60. Nemes L, Kiss A. Social media sentiment analysis based on COVID-19. Journal of Information and Telecommunication 2020 Jul 14:1-15. [doi: 10.1080/24751839.2020.1790793]

61. Clyne W, Pezaro S, Deeny K, Kneafsey R. Using Social Media to Generate and Collect Primary Data: The \#ShowsWorkplaceCompassion Twitter Research Campaign. JMIR Public Health Surveill 2018 Apr 23;4(2):e41 [FREE Full text] [doi: 10.2196/publichealth.7686] [Medline: 29685866]

62. Walker P, Whittaker C, Watson OJ, Baguelin M, Winskill P, Hamlet A, et al. The impact of COVID-19 and strategies for mitigation and suppression in low- and middle-income countries. Science 2020 Jul 24;369(6502):413-422 [FREE Full text] [doi: 10.1126/science.abc0035] [Medline: 32532802]

\section{Abbreviations \\ mHealth: mobile health \\ NHS: National Health Service}

Edited by G Eysenbach; submitted 24.09.20; peer-reviewed by $R$ Safari, $R$ Gore; comments to author 09.10.20; revised version received
26.10.20; accepted 28.10.20; published 03.12.20
Please cite as:
Berkovic D, Ackerman IN, Briggs AM, Ayton D
Tweets by People With Arthritis During the COVID-19 Pandemic: Content and Sentiment Analysis
J Med Internet Res 2020;22(12):e24550
URL: $\underline{\text { https://www.jmir.org/2020/12/e24550 }}$
doi: $\underline{10.2196 / 24550}$
PMID: $\underline{3170802}$
(page number not for citation purposes) 
CDanielle Berkovic, Ilana Ackerman, Andrew M Briggs, Darshini Ayton. Originally published in the Journal of Medical Internet Research (http://www.jmir.org), 03.12.2020. This is an open-access article distributed under the terms of the Creative Commons Attribution License (https://creativecommons.org/licenses/by/4.0/), which permits unrestricted use, distribution, and reproduction in any medium, provided the original work, first published in the Journal of Medical Internet Research, is properly cited. The complete bibliographic information, a link to the original publication on http://www.jmir.org/, as well as this copyright and license information must be included. 